\title{
Abnormal regulation of carbohydrate metabolism in primary gout
}

\author{
HERBERT S. DIAMOND, ANNE C. CARTER, AND ELAINE B. FELDMAN \\ From the Department of Medicine, State University of New York, \\ Downstate Medical Center, Brooklyn, N.Y.
}

Increased levels of circulating triglycerides (Feldman and Wallace, 1964) and an increased incidence of carbohydrate intolerance (Berkowitz, 1966) are common features of gout. The present study was designed to provide more complete details of carbohydrate and lipid metabolism in primary gout, and to investigate the relationship of abnormalities to the mechanism responsible for hyperuricaemia, renal retention of uric acid, or uric acid overproduction. The contribution of obesity to observed abnormalities of carbohydrate and lipid metabolism was assessed.

\section{Methods}

Nineteen men and two women were studied (Table I). Seventeen patients were admitted to a clinical research centre. Four nonadmitted, ambulatory patients (Cases 13,
$17,18,21)$ were studied in the same unit. Body weight of all patients had been stable for the preceding 3 months. Carbohydrate intake in all patients was estimated from dietary history to be greater than $150 \mathrm{~g}$ carbohydrate daily (American Diabetes Association Committee on Statistics, 1969). All patients admitted to the centre were given isocaloric purine 'free' diets containing more than $50 \%$ calories from carbohydrate. Specific therapy for gout was withdrawn for at least 3 days before investigations; for most patients such therapy was withdrawn for several weeks. No patients had overt diabetes mellitus, liver disease, or blood urea nitrogen greater than $20 \mathrm{mg} / 100 \mathrm{ml}$. Arteriosclerotic cardiovascular disease was defined by the criteria of the New York Heart Association. Excessive alcohol use was defined by regular consumption sufficients to have interfered with social function or produce symptoms of intoxication. All eight such patients had not consumed alcohol for at least 2 weeks before the study.

Table I Clinical characteristics

\begin{tabular}{|c|c|c|c|c|c|c|c|c|c|}
\hline Case no. & $\begin{array}{l}\text { Age } \\
\text { (yrs) }\end{array}$ & $\operatorname{Sex}$ & & $\begin{array}{l}\text { Height } \\
(\mathrm{cm})\end{array}$ & $\begin{array}{l}\text { Weight } \\
(k g)\end{array}$ & Relative weight* & Hypertension $\dagger$ & $A S \ddagger$ & Use of alcohol \\
\hline 1 & 56 & M & & $162 \cdot 5$ & $63 \cdot 6$ & 102 & - & - & + \\
\hline 2 & 57 & $\mathbf{M}$ & & $175 \cdot 0$ & $90 \cdot 9$ & 127 & - & - & - \\
\hline 3 & 53 & $\mathbf{M}$ & & $165 \cdot 0$ & 79.5 & 124 & + & - & - \\
\hline 4 & 49 & $\mathbf{M}$ & & $170 \cdot 0$ & $61 \cdot 4$ & 91 & - & - & + \\
\hline 5 & 42 & $\mathbf{M}$ & & $172 \cdot 5$ & $77 \cdot 3$ & 111 & + & - & - \\
\hline 6 & 34 & $\mathbf{M}$ & & $177 \cdot 5$ & $77 \cdot 3$ & 105 & + & - & - \\
\hline 7 & 41 & F & & $157 \cdot 5$ & $59 \cdot 1$ & 106 & - & + & - \\
\hline 8 & 63 & $\mathbf{M}$ & & $172 \cdot 5$ & $77 \cdot 3$ & 111 & - & - & + \\
\hline 9 & 21 & $\mathbf{M}$ & & $170 \cdot 0$ & $70 \cdot 4$ & 104 & - & - & - \\
\hline 10 & 44 & $\mathbf{M}$ & & $177 \cdot 5$ & $86 \cdot 4$ & 117 & + & + & + \\
\hline 11 & 68 & $\mathbf{F}$ & & $147 \cdot 5$ & $85 \cdot 0$ & 170 & + & - & - \\
\hline 12 & 61 & $\mathbf{M}$ & & $167 \cdot 5$ & $54 \cdot 5$ & 83 & - & - & + \\
\hline 13 & 39 & & , & $172 \cdot 5$ & $100 \cdot 0$ & 138 & + & - & - \\
\hline 14 & 43 & $\mathbf{M}$ & 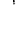 & $177 \cdot 5$ & 95.5 & 130 & - & - & + \\
\hline 15 & 38 & M & & $177 \cdot 5$ & $81 \cdot 8$ & 111 & - & - & - \\
\hline 16 & 66 & $\mathbf{M}$ & & $167 \cdot 5$ & $81 \cdot 8$ & 122 & + & + & + \\
\hline 17 & 62 & $\mathbf{M}$ & & $170 \cdot 0$ & $73 \cdot 2$ & 106 & + & + & - \\
\hline 18 & 35 & $\mathbf{M}$ & & $164 \cdot 0$ & $91 \cdot 8$ & 137 & - & - & + \\
\hline 19 & 45 & $\mathbf{M}$ & & $162 \cdot 5$ & $73 \cdot 2$ & 100 & - & - & - \\
\hline 20 & 52 & $\mathbf{M}$ & & $165 \cdot 0$ & $77 \cdot 3$ & 116 & + & - & - \\
\hline 21 & 44 & $\mathbf{M}$ & & 160.0 & 90.5 & 145 & - & - & - \\
\hline
\end{tabular}

* Relative weight $=$ percent of ideal weight.

+ Hypertension = diastolic blood pressure $100 \mathrm{mmHg}$ or greater.

$\ddagger \mathrm{AS}=$ symptomatic arteriosclerotic cardiovascular disease.

$+=$ present; $-=$ absent.

Accepted for publication May 10, 1974.

This work was presented in part before the International Symposium commemorating the 50thAnniversay of Insulin, in Jerusalem, Israel, November 2, 1971, and before the American Rheumatism Association in Dallas, Texas, June 8, 1972. 
A 6-hr oral glucose tolerance test was carried out using a standard dose of $100 \mathrm{~g}$ glucose. Patients received only water after supper the evening before. Tests were started at 8 a.m., with hospitalized patients remaining in bed after awakening. Ambulatory patients were put to bed for a minimum of one-half hour after arrival before starting tests. All patients were at bed rest for the duration of the test. An indwelling scalp vein needle was inserted into an arm vein and was kept patent with a slow infusion of isotonic saline. All blood samples were obtained free-flowing. Control blood samples were drawn at -30 and 0 minutes before glucose ingestion. Subsequent blood samples were obtained $\frac{1}{2}, 1,2,3,4,5$, and $6 \mathrm{hrs}$ after the oral glucose load. Blood for lipid analyses was collected into test tubes containing dry EDTA (ethylene diamine tetra-acetate, disodium). Blood for glucose and hormone measurements was collected in heparinized syringes. Samples were immediately cooled by placing the test tubes in an ice bath; the plasma was separated within $\mathbf{3 0}$ minutes in a refrigerated centrifuge at $4^{\circ} \mathrm{C}$ and stored frozen at $-5^{\circ} \mathrm{C}$.

Fourteen hospitalized patients (Cases 1-12, 14, and 15) were placed on a high carbohydrate, low purine formula diet (Farquhar, Frank, Gross, and Reaven, 1966) for 6 days at a calorie level to maintain constant weight; $85 \%$ of calories were carbohydrate ( $83 \%$ from Dexin, BurroughsWellcome, N.Y., $17 \%$ from skimmed milk), and $15 \%$ calories were protein (skimmed milk powder). The formula was given in 4 equicaloric feedings at 8 and 11 a.m. and 2 and 5 p.m. The formula was consumed steadily during a 30-minute period. On days 1,3 , and 7 of this regimen blood was obtained for measurement of lipids and lipoproteins before the morning feeding. Responses of plasma glucose, insulin, free fatty acids, glycerol, and growth hormone to the formula were also measured on the same days by sampling before the 8 a.m. formula feeding, and 1 and $2 \mathrm{hrs}$ after the feeding was started.

Plasma cholesterol and triglycerides were determined by Technicon Autoanalyser methods N-24A and N-78, using isopropanol extracts analysed separately. Plasma phospholipids were measured by the method of Bartlett (Bartlett, 1959). Free fatty acids were extracted from plasma and determined with the Autoanalyser (Dalton and Kowalski, 1967). Glycerol was determined with the Autoanalyser on protein-free filtrates of plasma prepared with perchloric acid (Ko and Royer, 1968). Lipoproteins were separated by thin film agarose gel electrophoresis (Pfizer) and quantified visually and in an Analytrol densitometer with microscan attachment (Beckman).

Plasma glucose was determined by the Autoanalyser glucose oxidase method. Plasma insulin and growth hormone were measured by radioimmunoassay (Rosselin, Assan, Yalow, and Berson, 1966). Glomerular filtration rate was estimated from endogenous creatinine clearance. Creatinine and uric acid clearances were performed and calculated using standard clearance techniques. Uric acid was determined by an automated enzymatic (uricase) spectrophotometric method (Crowley and Alton, 1968). Creatinine was determined by Autoanalyser method 11b. Urinary uric acid excretion represented the mean of at least two 24-hr urine collections obtained after at least 3 days on a purine-free, low protein, isocaloric diet. Most patients had been on this diet for at least 5 days before the first 24-hr urine collection was obtained. Eight patients who excreted greater than $590 \mathrm{mg}$ uric acid per 24-hr urine collection were considered to overproduce uric acid. Six patients with 24-hr urinary uric acid excretion less than $590 \mathrm{mg}$ and urinary uric acid/creatinine ratios of less than 0.20 were considered underexcretors of uric acid.

\section{Results}

The clinical characteristics of the patients and the features of their gout are summarized in Tables $I$ and II.

Mean data from the oral glucose tolerance tests are

Table II Characteristics of gout

\begin{tabular}{|c|c|c|c|c|c|c|c|c|c|c|}
\hline $\begin{array}{l}\text { Case } \\
\text { no. }\end{array}$ & $\begin{array}{l}\text { Selum } \\
\text { uric } \\
\text { acid } \\
(\mathrm{mg} / 100 \mathrm{ml})\end{array}$ & $\begin{array}{l}24-h r \\
\text { urine uric } \\
\text { acid } \\
(m g / 24 h r s)\end{array}$ & $\begin{array}{l}\text { Age } \\
\text { onset of } \\
\text { gout } \\
\text { (yrs) }\end{array}$ & Podagra & $\begin{array}{l}\text { Urate } \\
\text { crystals in } \\
\text { joint } \\
\text { fluid }\end{array}$ & $\begin{array}{l}\text { Uric acid } \\
\text { renal } \\
\text { stone }\end{array}$ & Tophi & $\begin{array}{l}\text { Response } \\
\text { to } \\
\text { colchicine }\end{array}$ & $\begin{array}{l}\text { Creatinine } \\
\text { clearance } \\
(\mathrm{ml} / \mathrm{min})\end{array}$ & $\begin{array}{l}\text { Uric acidl } \\
\text { creatinine } \\
\text { excretion }\end{array}$ \\
\hline $\begin{array}{r}1 \\
2 \\
3 \\
4 \\
5 \\
6 \\
7 \\
8 \\
9 \\
10 \\
11 \\
12 \\
13 \\
14 \\
15 \\
16 \\
17 \\
18 \\
19 \\
20 \\
21\end{array}$ & $\begin{array}{r}10 \cdot 8 \\
9 \cdot 1 \\
10 \cdot 0 \\
4 \cdot 9 \\
7 \cdot 9 \\
8 \cdot 9 \\
8 \cdot 6 \\
8 \cdot 8 \\
6 \cdot 9 \\
6 \cdot 9 \\
8 \cdot 7 \\
7 \cdot 9 \\
7 \cdot 8 \\
10 \cdot 8 \\
8 \cdot 4 \\
8 \cdot 4 \\
6 \cdot 1 \\
7 \cdot 2 \\
9 \cdot 3 \\
10 \cdot 3 \\
8 \cdot 2\end{array}$ & $\begin{array}{l}149 \\
620 \\
300 \\
253 \\
202 \\
628 \\
300 \\
820 \\
960 \\
220 \\
760 \\
130 \\
694 \\
336 \\
613 \\
328 \\
\text { Unknown } \\
\text { Unknown } \\
848 \\
62 \\
\text { Unknown }\end{array}$ & $\begin{array}{l}40 \\
47 \\
51 \\
49 \\
39 \\
32 \\
36 \\
53 \\
17 \\
30 \\
49 \\
55 \\
30 \\
40 \\
36 \\
54 \\
50 \\
31 \\
33 \\
49 \\
44\end{array}$ & $\begin{array}{l}+ \\
+ \\
+ \\
+ \\
+ \\
+ \\
+ \\
+ \\
+ \\
+ \\
+ \\
+ \\
+ \\
+ \\
+ \\
+ \\
+ \\
+ \\
+ \\
+\end{array}$ & $\begin{array}{l}+ \\
+ \\
\text { Unknown } \\
+ \\
+ \\
+ \\
+ \\
+ \\
\text { Unknown } \\
+ \\
+ \\
+ \\
+ \\
+ \\
\text { Unknown } \\
\text { Unknown } \\
+ \\
+ \\
\text { Unknown } \\
\text { Unknown } \\
-\end{array}$ & $\begin{array}{l}- \\
- \\
- \\
- \\
- \\
- \\
- \\
- \\
- \\
- \\
+ \\
- \\
- \\
- \\
- \\
- \\
- \\
+\end{array}$ & $\begin{array}{l}+ \\
+ \\
- \\
+ \\
\bar{t} \\
- \\
- \\
+ \\
+ \\
- \\
+ \\
+ \\
+ \\
- \\
-\end{array}$ & $\begin{array}{l}+ \\
+ \\
+ \\
+ \\
+ \\
+ \\
+ \\
+ \\
+ \\
+ \\
+ \\
+ \\
+ \\
+ \\
+ \\
+ \\
+ \\
+ \\
+ \\
+\end{array}$ & $\begin{array}{l}62 \\
102 \\
102 \\
117 \\
96 \\
146 \\
40 \\
115 \\
135 \\
106 \\
52 \\
41 \\
138 \\
105 \\
110 \\
59 \\
\text { Unknown } \\
\text { Unknown } \\
135 \\
54 \\
\text { Unknown }\end{array}$ & $\begin{array}{l}0.14 \\
0.24 \\
0.24 \\
0.14 \\
0.25 \\
0.28 \\
0.41 \\
0.27 \\
0.30 \\
0.20 \\
0.32 \\
0.11 \\
0.40 \\
0.25 \\
0.47 \\
0.28 \\
\text { Unknown } \\
\text { Unknown } \\
0.52 \\
0.08 \\
\text { Unknown }\end{array}$ \\
\hline
\end{tabular}


shown in Fig. 1a. Nine patients were considered diabetic on the basis of either glucose levels of $185 \mathrm{mg} / 100 \mathrm{ml}$ or greater at 1 hour and $140 \mathrm{mg} / 100$ $\mathrm{ml}$ or greater at $2 \mathrm{hrs}$ after glucose, or when the sum of plasma glucose values at $0,1,2$, and $3 \mathrm{hrs}$ exceeded $600 \mathrm{mg} / 100 \mathrm{ml}$ (Fajans and Conn, 1954). The classification of glucose tolerance as normal or abnormal was not changed by adjusting criteria for age above 50 .

Ten patients were considered obese whose body weight was $115 \%$ or greater by reference to mean
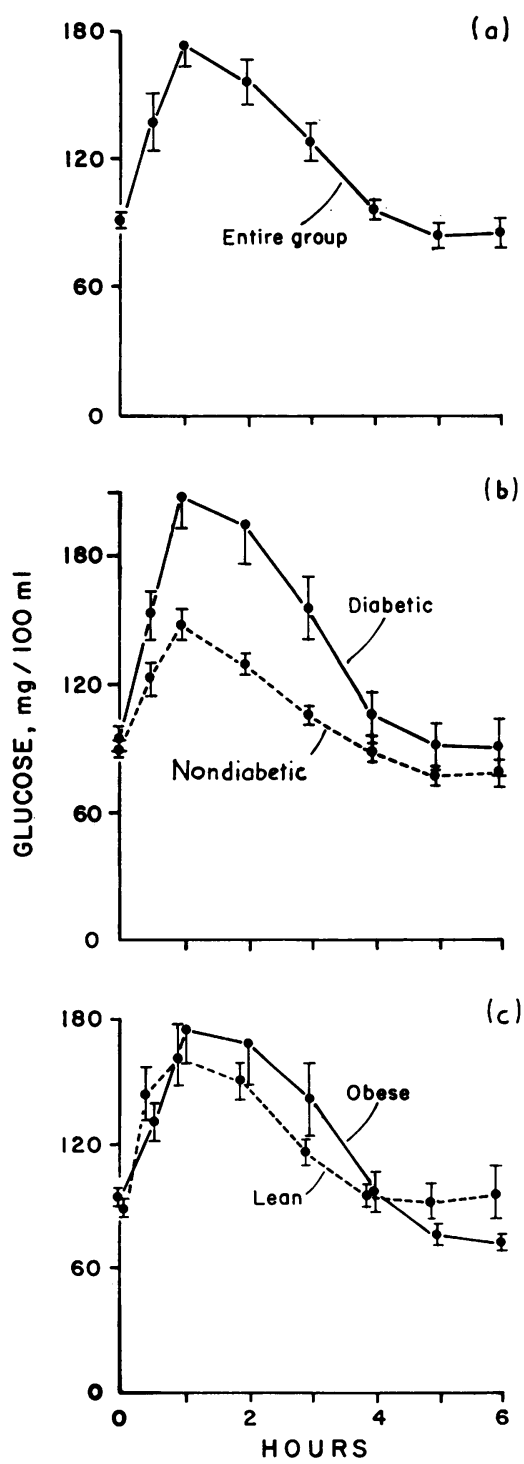

Fig. 1 Mean values of plasma glucose during 6-hr oral glucose tolerance tests $(100 \mathrm{~g})$. Values at 0 time are the means of two measurements. In this and subsequent figures, the vertical bars represent \pm 1 SEM. See text ideal weight for height according to the Metropolitan Life Insurance Co. tables. Eleven patients were considered to be non-obese whose body weight was less than $115 \%$ of mean ideal weight (Bagdade, Bierman, and Porte, 1967). The incidence of diabetes was greater among obese patients (6 of 10) than among non-obese patients (3 to 11). However, impaired glucose tolerance was not entirely attributed to obesity since mean glucose tolerance was similar in the ten obese patients and eleven non-obese patients (Fig. 1c).

Basal plasma insulin values in gouty patients increased tenfold to peak levels $2 \mathrm{hrs}$ after oral glucose and did not return to baseline until 5 or $6 \mathrm{hrs}$ after glucose (Fig. 2a). Basal insulin values correlated significantly $(r=0.47 ; \mathrm{P}<0.05)$ with per cent. ideal body weight. Mean basal insulin values in obese patients were significantly greater $(0.01<\mathrm{P}<0.02)$ than the mean basal insulin value observed in lean patients (Fig. 2c). The early (30-minute) insulin response to glucose was impaired in the obese patients with either normal or abnormal glucose tolerance in comparison to the non-obese groups. From 1 to $4 \mathrm{hrs}$ mean insulin values were 120 to $175 \%$ greater in obese patients compared to the non obese group. The increased insulin secretion in the diabetic gouty patients was entirely attributed to hyperinsulinism in the obese-diabetic group (Fig. $2 d)$. The lean diabetic group secreted decreased amounts of insulin (Fig. $2 d$ ).

The mean basal growth hormone value in 21 patients was $1.0 \pm 0.24 \mathrm{ng} / \mathrm{ml}$. In nineteen patients, 2 basal determinations were made averaging $0.50 \pm 0.13 \mathrm{ng}$ and $0.97 \pm 0.27 \mathrm{ng} 30$ minutes later. Mean growth hormone values paradoxically increased one-half hour after oral glucose, then declined toward baseline by $2 \mathrm{hrs}$. A small late mean peak was observed $5 \mathrm{hrs}$ after glucose (Fig. $3 a$ ). One-half hour after oral glucose, mean growth hormone secretion was $11.1 \pm 7.9 \mathrm{ng} / \mathrm{ml}$ in the non-obese patients, compared to $0.6 \pm 0.1$ in the obese patients $(P<0.01)$. Significant increases in growth hormone at 30 minutes occurred in six of eleven non-obese patients (Figure $3 c$ ). The increase in growth hormone at $\mathbf{3 0}$ minutes was found in nonobese patients with either normal or abnormal glucose tolerance, though the increase was more pronounced in the latter group (Fig. 3b). There was no increase in growth hormone secretion at $5 \mathrm{hrs}$ in the non-obese patients (Fig. $3 c$ ). This abnormal pattern of growth hormone secretion after glucose was not observed in the ten obese gouty patients or in similar tests in two groups of control subjects observed under similar conditions in our laboratory: 33 nondiabetic, nongouty, hypertriglyceridaemic subjects and eight normal subjects.

Basal values for free fatty acids in gouty patients $(631 \pm 43 \cdot 3 \mu \mathrm{Eq} / 1$.) did not differ significantly from a 

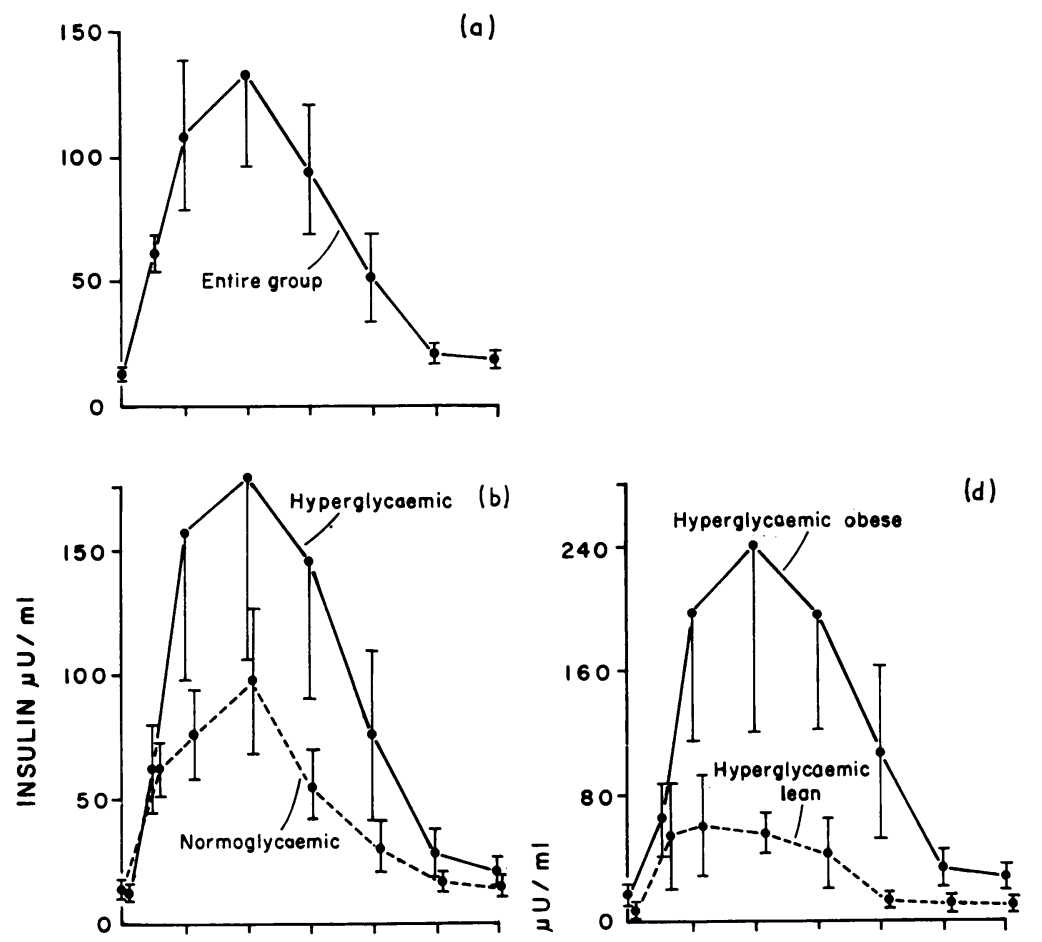

FIG. 2 Mean values of plasma insulin during 6-hr oral glucose tolerance tests $(100 \mathrm{~g})$. See Fig. 1 and text
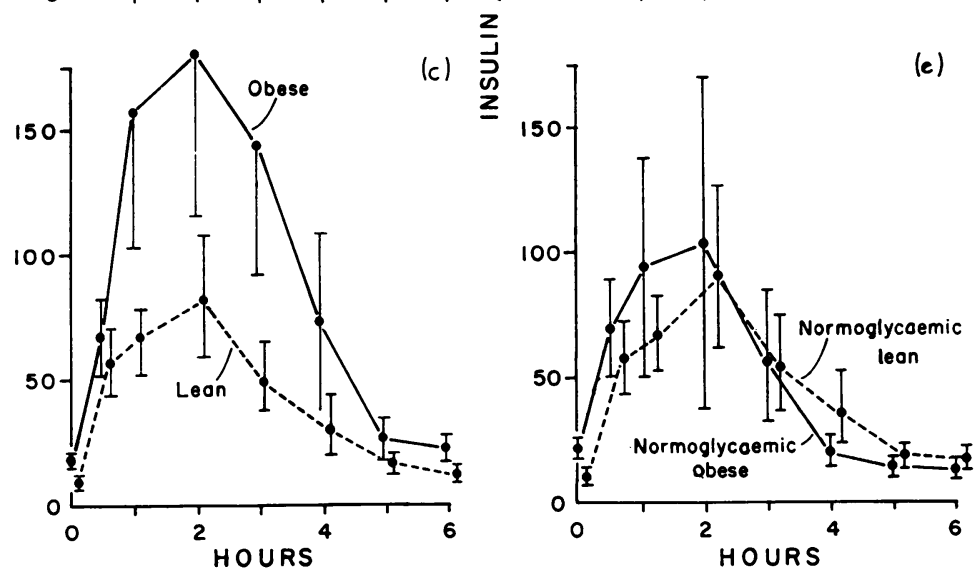

mean value of $548 \mu \mathrm{Eq} / \mathrm{l}$. obtained in fourteen healthy subjects studied in this laboratory (Feldman and Carter, 1971). Free fatty acids decreased by one-sixth sluggishly $4 \mathrm{hrs}$ after glucose, and rebounded above baseline at $6 \mathrm{hrs}$ (Fig. 4). A steeper $30 \%$ decrease in plasma glycerol from basal levels occurred $3 \mathrm{hrs}$ after oral glucose (Fig. 5). There was no significant difference in the responses of circulating free fatty acids and glycerol to oral glucose in the two groups of patients with normal and abnormal glucose tolerance, nor in obese compared to non-obese patients.

There was a significant correlation between serum uric acid and plasma glucose $\mathbf{1 ~ h r}$ after glucose loading ( $r=0.53 ; \mathrm{P}<0.01)$. Serum uric acid levels did not differ significantly in patients with normal or abnormal glucose tolerance, averaging $7 \cdot 8 \pm 0.4$ and $9.2 \pm 0.4 \mathrm{mg} / 100 \mathrm{ml}$, respectively. Four of eight patients considered to be 'overproducers' of uric acid and three of six 'underexcretors' had abnormal glucose tolerance. Patterns of insulin and growth hormone secretion after glucose loading were similar in overproducers and underexcretors.

Baseline plasma lipid values (Fig. 6) were the mean of two measurements. Mean values for gouty patients were: triglycerides $188 \pm 47.9 \mathrm{mg} / 100 \mathrm{ml}$; cholesterol $209 \pm 14.5 \mathrm{mg} / 100 \mathrm{ml}$; phospholipids $251 \pm 10.8$ $\mathrm{mg} / 100 \mathrm{ml}$. Hypertriglyceridaemia $(180 \mathrm{mg} / 100 \mathrm{ml}$ or 

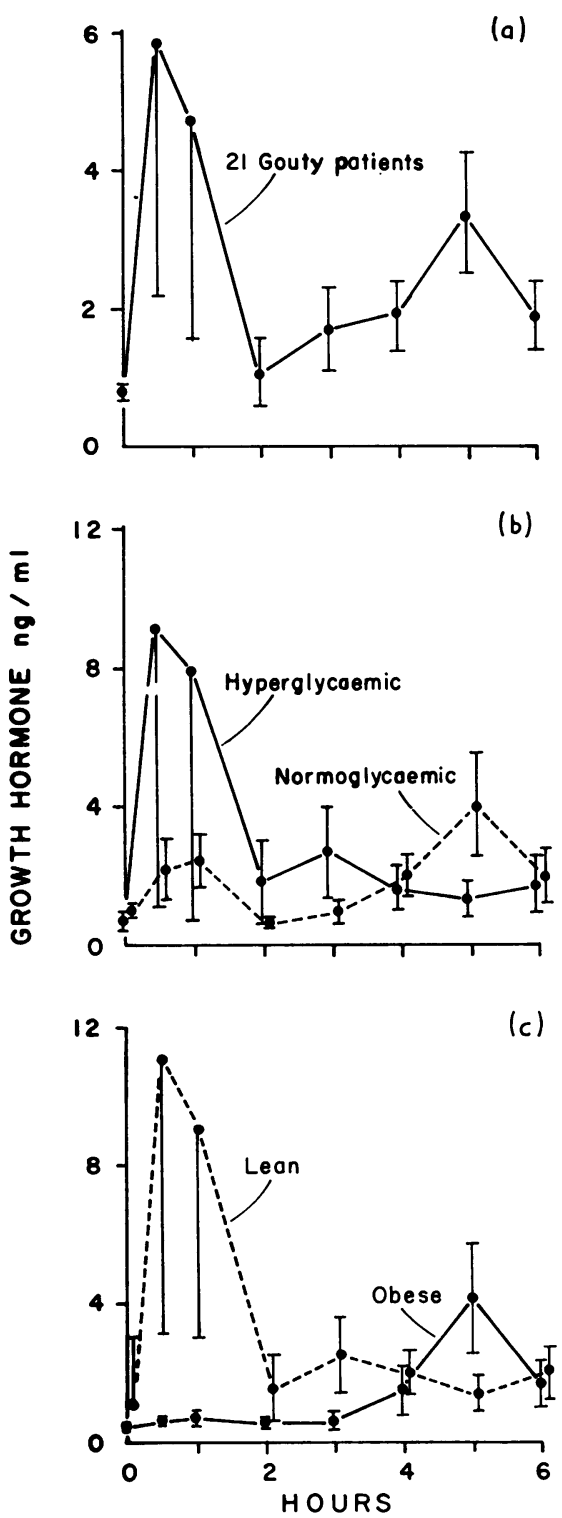

FIG. 3 Mean values of plasma growth hormone during 6-hr oral glucose tolerance tests $(100 \mathrm{~g})$. See Fig. 1 and text

greater) was noted in six patients. Hypercholesterolaemia $(270 \mathrm{mg} / 100 \mathrm{ml}$ or greater) was observed in three patients. The lipoprotein pattern was normal in ten patients, showed increased $\beta$-lipoprotein in 6 patients, and chylomicrons were observed in two patients. Pre- $\beta$-lipoprotein was increased in ten patients; the increase was slight in eight patients, and moderate or marked in one patient each. Plasma triglycerides did not differ significantly in patients with normal or abnormal glucose tolerance, averaging $193 \pm 61$ and $181 \pm 47 \mathrm{mg} / 100 \mathrm{ml}$, respectively.

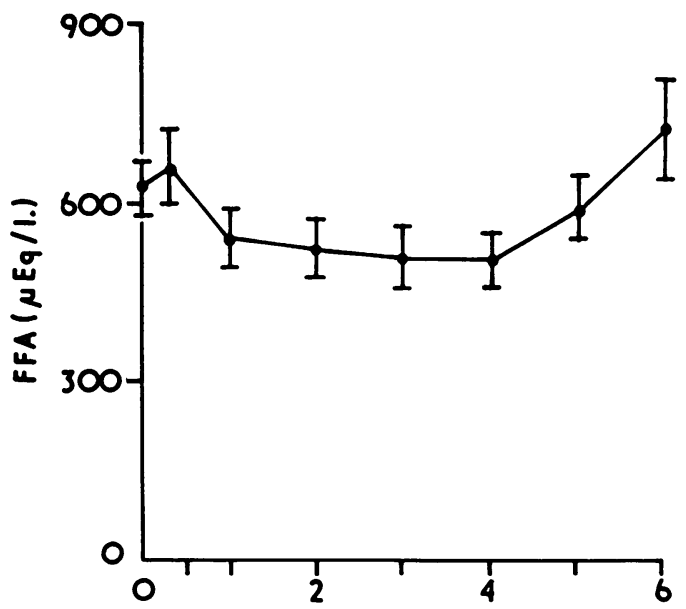

Hours

FIG. 4 Mean values of plasma free fatty acids during 6-hr oral glucose tolerance tests $(100 \mathrm{~g})$. See Fig. 1 and text

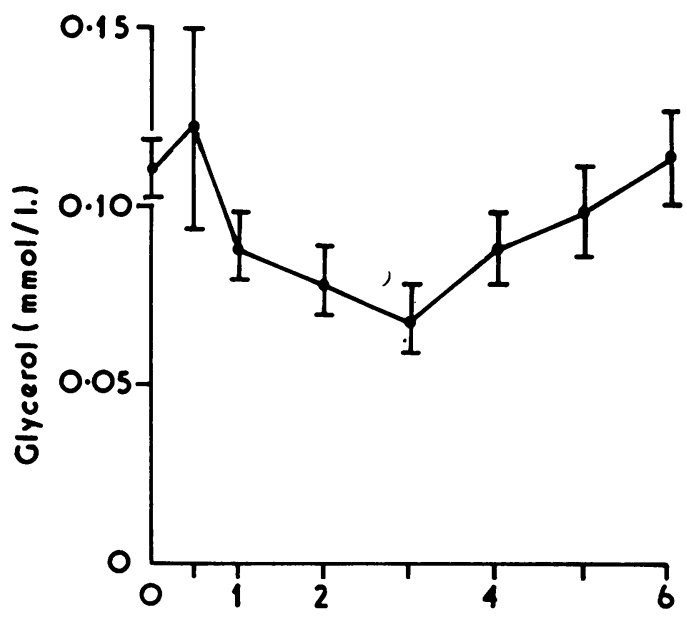

Hours

FIG. 5 Mean values of plasma glycerol during 6-hr oral glucose tolerance test $(100 \mathrm{~g})$. See Fig. 1 and text

Triglyceride values in obese patients were greater than those of thin patients, $264 \pm 75$ compared to $119 \pm 17$ $\mathrm{mg} / 100 \mathrm{ml}$. Triglyceride levels were similar in eight 'overproducers' of uric acid compared with six normal excretors, averaging $167 \pm 47.9$ and $150 \pm 36$ $\mathrm{mg} / 100 \mathrm{ml}$, respectively.

In nine healthy control subjects, mean age 40 years (range 21-58 years), body weight range of $85-165 \%$ of ideal weight with normal glucose tolerance tests, no family history of diabetes mellitus, and normal serum uric acid concentrations $(5.4 \pm 0.4 \mathrm{mg} / 100$ $\mathrm{ml}$ ), the mean plasma triglycerides were $101 \pm 13$ $\mathrm{mg} / 100 \mathrm{ml}$ and mean plasma cholesterol was $196 \pm 38$ $\mathrm{mg} / 100 \mathrm{ml}$. 


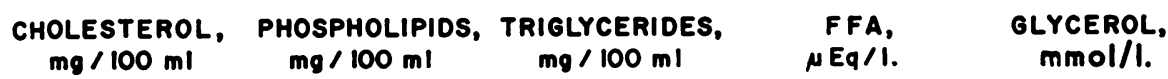

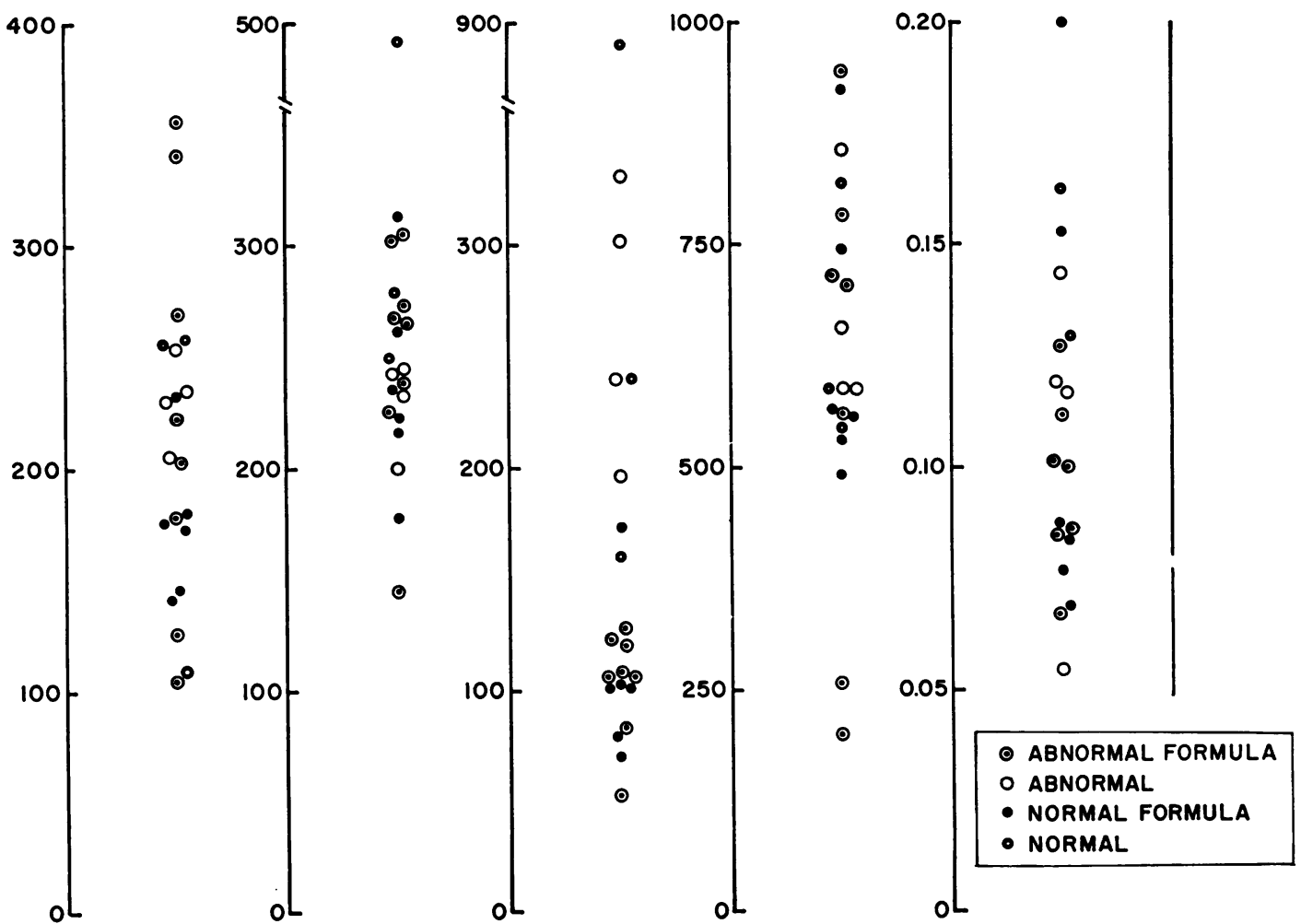

FIG. 6 Individual baseline plasma lipids of 21 gouty patients. Each value represents the mean of two determinations of plasma samples obtained after an overnight fast. O depict patients with normal glucose tolerance; $\bullet$ represent the subgroup given the formula diet. $\bigcirc$ represent patients with some abnormality of glucose tolerance; $\odot$ were placed on the formula diet

Carbohydrate inducibility of hyperlipidaemia in the patients given the high carbohydrate formula diet was similar to that reported in normal subjects (Glueck, Levy, and Fredrickson, 1969). The mean triglyceride increment was $42 \%$ over preformula values. Pre- $\beta$-lipoprotein increased to moderate levels, on average. Circulating cholesterol and phospholipid values were unchanged. The mean response of glucose, free fatty acids, glycerol, insulin, and growth hormone to the feeding was similar initially, and on days 3 and 7 of the formula (Fig. 7).

\section{Discussion}

The present data indicate that several abnormalities of carbohydrate and lipid metabolism and their normal control mechanisms are frequent in patients with primary gout. Although some of these abnormalities may reflect the high frequency of obesity among the gouty patients, obesity did not account for all of the abnormalities observed.
Although glucose intolerance is a frequent feature of gout (McKechnie, 1964; Mikkelsen, 1965; Denis and Launay, 1969), the significance of this association has been questioned or attributed to the high incidence of obesity in gouty patients (McKechnie, 1964, Wiedemann, Rose, and Schwartz, 1972; Boyle, McKiddie, Buchanan, Jasani, Gray, Jackson, and Buchanan, 1969). The greater incidence of glucose intolerance in obese gouty patients $(66 \%)$ than in non-obese gouty patients $(27 \%)$ in the present study is consistent with the latter interpretation. However, the mean glucose tolerance in the present study was similar in obese and non-obese gouty patients (Fig. 1c), suggesting that glucose intolerance was not entirely related to obesity. Moreover, with exclusion of gouty patients with increased fasting blood glucose (overt diabetes), the prevalence of abnormal glucose tolerance or chemical diabetes in non-obese gouty subjects, mean age 46 , was $27 \%$. This incidence is greater than the prevalence in comparable nongouty, nonhyperlipidaemic subjects in this institution. 

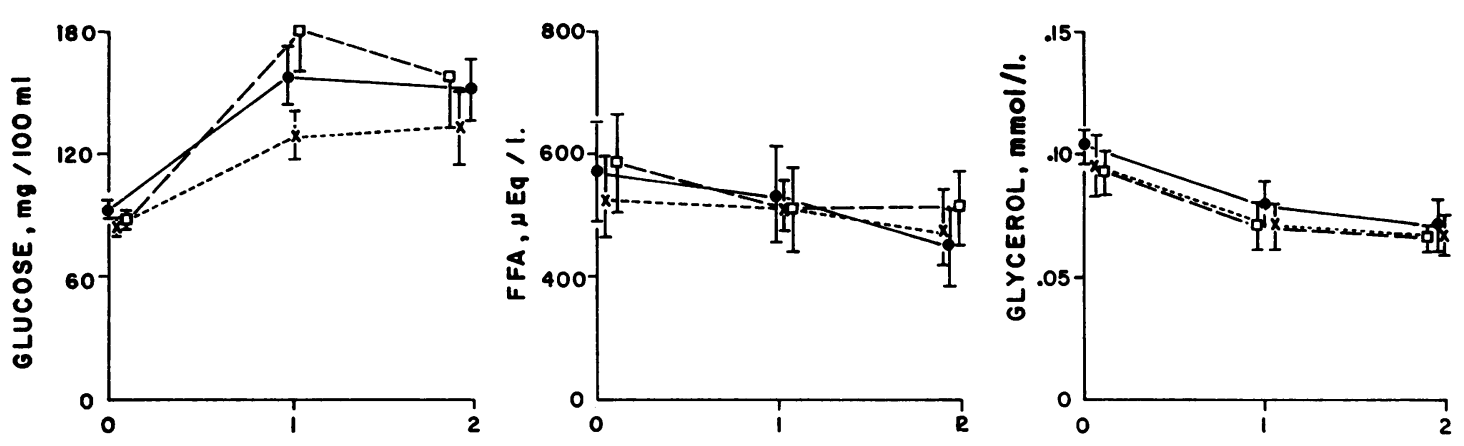

Hours
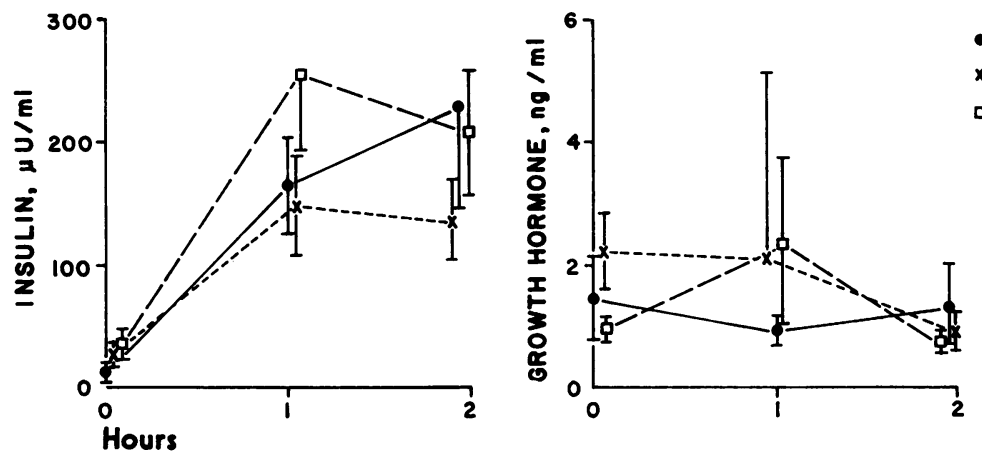

FIG. 7 Effects of carbohydrate formula feeding on pre- and postprandial nutrients and hormones. Mean pre-, 1-, and 2-hr postprandial values for glucose, FFA, glycerol, insulin, and growth hormone in 14 gouty patients are graphed on days 1 and 3, and after 6 days of feeding with an isocaloric diet of $85 \%$ carbohydrate and $15 \%$ protein

In the present study, basal insulin levels correlated with body weight, confirming data reported previously in obese patients with or without hyperlipidaemia or diabetes mellitus (Bagdade and others, 1967). Relative hyperinsulinism was observed only in obese gouty patients and was therefore attributed entirely to obesity. Non-obese gouty patients with abnormal glucose tolerance showed deficient insulin secretion relative to their blood glucose levels. Peak insulin secretion was delayed to $2 \mathrm{hrs}$ in both obese and lean patients suggesting an abnormality in insulin release which was independent of obesity.

Early secretion of growth hormone in response to glucose was observed in some non-obese gouty patients. This is consistent with the finding of depressed levels of growth hormone after glucose in obesity (Yalow, Glick, Roth, and Berson, 1965). This abnormality was not associated with hyperinsulinism and occurred in patients with both normal and abnormal glucose tolerance. The early secretion of growth hormone after glucose suggests impairment of the usual hypothalamic inhibitory control by glucose. The failure of the secondary rise of growth hormone in gouty patients with early postglucose growth hormone secretion may result from autofeedback suppression by the initial growth hormone peak (Abrams, Grumbach, and Kaplan, 1971). The effect of uric acid and other purines on hypothalamic function and polypeptide hormone secretion is unknown, though uric acid itself is not found in excess in cerebrospinal fluid in hyperuricaemia (Rosenbloom, Kelley, Miller, Henderson, and Seegmiller, 1967). Diabetes is not usually accompanied by excess growth hormone secretion except in acromegaly (Porte and Bagdade, 1970).

The patients with gout manifested delayed and decreased reduction in plasma free fatty acids after glucose, in contrast to the decrease of about $50 \%$ observed in normal subjects in this laboratory and by others (Hales and Randle, 1963). This finding is unexplained since fatty acid response to oral glucose was similar in obese and thin patients, those with normal or abnormal glucose tolerance, and in overproducers and underexcretors of purine.

The $29 \%$ incidence of hypertriglyceridaemia in these gouty patients is similar to that reported previously (Feldman and Wallace, 1964; Rosselin and others, 1966), and is less than rates up to $75 \%$ reported by others (Berkowitz, 1966; Barlow, 1968). The mean triglyceride value in the present study agrees with the mean level of $174 \mathrm{mg} / 100 \mathrm{ml}$ reported recently (Wiedemann and others, 1972). Other investigators have found no correlation in gouty patients between hypertriglyceridaemia and renal 
disease, obesity, or alcoholism (Emmerson and Knowles, 1971). In the present study, hypertriglyceridaemia was not explained by obesity or impaired glucose tolerance. The present data indicate no difference in triglyceride levels in gouty patients who are 'overproducers' in contrast to patients whose renal handling of uric acid is defective.

The gouty patients developed lipaemia with triglyceride increments of 40 to $100 \%$, in response to high carbohydrate diet similar to normal, diabetic, and lipaemic subjects (Glueck and others, 1969). This finding supports the concept that the fundamental abnormality is a rise in plasma triglycerides on a basal diet, rather than the response to a high carbohydrate diet (Bierman and Porte, 1968).

Thus, several apparently unrelated abnormalities of carbohydrate and lipid metabolism are prevalent in patients with gout. Several different mechanisms appear to underlie these abnormalities. Hyperinsulinism and associated glucose intolerance was related to obesity. A diminished response of free fatty acids to glucose loading was noted in all groups of gouty subjects and thus might be secondary to gout or hyperuricaemia. The relationships between hypertriglyceridaemia or early secretion of growth hormone and gout are obscure and are not explained by the increased frequency of glucose intolerance or obesity in gouty patients. The possibilities that these abnormalities may reflect primary metabolic errors in control of carbohydrate or lipid metabolism related to the aetiology of gout or are secondary to factors associated with gout, such as alcoholism, require further investigation.

\section{Summary}

Carbohydrate and lipid metabolism were studied in 21 patients, mean age 48 , with primary gout. Ten patients were obese, eleven were lean. No patient had overt diabetes mellitus, liver disease, or azotaemia.

Abnormal glucose tolerance occurred in nine of 21 patients. The prevalence of diabetes was increased in both obese and thin patients, but the prevalence was greater among obese patients (6 of 10) than among non-obese patients ( 3 of 11 ). Insulin secretion was increased only in the obese-diabetic group.

One-half hour after oral glucose, mean growth hormone secretion was $11.1 \pm 7.9 \mathrm{ng} / \mathrm{ml}$ in the nonobese gouty patients compared to $0.6 \pm 0.1$ in the obese patients $(\mathrm{P}<0.01)$. This abnormality was not associated with hyperinsulinism and occurred in patients with both normal and abnormal glucose tolerance. All subgroups of the gouty patients manifested delayed and decreased (one-sixth) reduction in plasma free fatty acids after glucose.

Hypertriglyceridaemia was observed in $29 \%$ of gouty patients. The gouty patients developed lipaemia in response to a high carbohydrate diet with triglyceride increments of $40-100 \%$, similar to normal, diabetic, and lipaemic subjects. None of the abnormalities observed could be related to uric acid overproduction or underexcretion. Several different mechanisms appear to underlie these abnormalities. Hyperinsulinism and associated glucose intolerance was related to obesity. The relationship between hypertriglyceridaemia or early secretion of growth hormone and gout is obscure and is not explained as secondary to glucose intolerance or obesity.

We thank Miss Tina Kaplan for expertly performing the radioimmunoassays, and the nurses and staff of the Clinical Research Center for their efforts in caring for our patients.

We thank Dr. I. A. Mirsky who kindly supplied the human insulin, and the Hormone Distribution Center of the Endocrinology Study Section of the NIH for the human growth hormone (NIH-GH-HS 1394) used for iodination and standard. Human growth hormone antibody used was SUNY GP-90.

This work was supported by grant RR-318 from the General Clinical Research Centers program of the Division of Research Resources, National Institutes of Health, Arthritis Foundation, and a grant from the Ayerst Laboratories. Equipment for lipoprotein electrophoresis was kindly provided by Pfizer Diagnostics Division, New York.

\section{References}

Abrams, R. L., Grumbach, M. M., AND Kaplan, S. L. (1971) J. clin. Invest., 50, 940 (The effect of administration of human growth hormone on the plasma growth hormone, cortisol, glucose and free fatty acid response to insulin: evidence for growth hormone autoregulation in man)

American Diabetes Association Committee On Statistics (1969) Diabetes, 18, 299 (Standardization of the oral glucose tolerance test)

Bagdade, J. D., Bierman, E. L., AND Porte, D., JR. (1967) J. clin. Invest., 46, 1549 (The significance of basal insulin levels in the evaluation of the insulin response to glucose in diabetic and non-diabetic subjects)

BarLow, K. A. (1968) Metabolism, 17, 289 (Hyperlipidemia in primary gout)

Bartlett, G. R. (1959) J. biol. Chem., 234, 466 (Phosphorus assay in column chromatography)

BERKowItz, D. (1966) J. Amer. med. Ass., 197, 77 (Gout, hyperlipidemia, and diabetes interrelationships)

Bierman, E. L., AND PORTE, D., JR. (1968) Ann. intern. Med., 68, 926 (Carbohydrate intolerance and lipemia)

Boyle, J. A., McKiddie, M., Buchanan, K. D., Jasani, M. K., Gray, H. W., Jackson, I. M. D., and Buchanan, W. W. (1969) Ann. rheum. Dis., 28, 374 (Diabetes mellitus and gout)

Crowley, L. V., ANd Alton, F. I. (1968) Amer. J. clin. Path.. 49, 285 (Automated analysis of uric acid) 
Dalton, C., AND Kowalski, C. (1967) Clin. Chem., 13, 744 (Automated colorimetric determination of free fatty acids in biologic fluids)

Denis, G., AND LAUnAY, M. P. (1969) Metabolism, 18, 770 (Carbohydrate intolerance in gout)

EMMERSON, B. T., AND KNOWLES, B. R. (1971) Ibid., 20, 721 (Triglyceride concentrations in primary gout and gout of chronic lead nephropathy)

Fajans, S. S., AND CoNN, J. W. (1954) Diabetes, 3, 296 (An approach to the prediction of diabetes mellitus by modification of the glucose tolerance test with cortisone)

Farquhar, J. W., Frank, A., Gross, R. C., and Reaven, G. M. (1966) J. clin. Invest., 45, 1648 (Glucose, insulin, and triglyceride responses to high and low carbohydrate diets in man)

Feldman, E. B., AND CARTER, A. C. (1971) J. clin. Endocr., 33, 8 (Circulating lipids and lipoproteins in women with metastatic breast carcinoma)

-, AND WALLACE, S. L. (1964) Circulation, 29, 508 (Hypertriglyceridemia in gout)

Glueck, C. J., Levy, R. I., AND Fredrickson, D. S. (1969) Diabetes, 18, 739 (Immunoreactive insulin, glucose tolerance, and carbohydrate inducibility in types II, III, IV and V hyperlipoproteinemia)

HALES, C. N., AND RANDLE, P. J. (1963) Lancet, 1, 790 (Effects of low-carbohydrate diet and diabetes mellitus on plasma concentrations of glucose, non-esterified fatty acid, and insulin during oral glucose tolerance tests)

Ko, H., AND RoYer, M. E. (1968) Analyt. Biochem., 26, 18 (Automated determination of glycerol in plasma)

MCKECHNIE, J. K. (1964) S. Afr. med. J., 38, 182 (Gout, hyperuricaemia and carbohydrate metabolism)

MikKelsen, W. M. (1965) Arthr. and Rheum., 8, 853 (The possible association of hyperuricemia and/or gout with diabetes mellitus)

Porte, D., AND BAGDADE, J. D. (1970) Ann. Rev. Med., 21, 219 (Human insulin secretion: an integrated approach)

Rosenbloom, F. M., Kelley, W. N., Miller, J., Henderson, J. F., and Seegmiller, J. E. (1967) J. Amer. med. Ass., 202, 175 (Inherited disorder of purine metabolism: correlation between central nervous system dysfunction and biochemical defects)

Rosselin, G., Assan, R., Yalow, R. S., AND Berson, S. A. (1966) Nature, 212, 355 (Separation of antibody-bound and unbound peptide hormones labelled with iodine-131 by talcum powder and precipitated silica)

Wiedemann, E., Rose, H. G., and SchwartZ, E. (1972) Amer. J. Med., 53, 299 (Plasma lipoproteins, glucose tolerance and insulin response in primary gout)

Yalow, R. S., Glick, S. M., Roth, J., AND Berson, S. A. (1965) Ann. N.Y. Acad. Sci., 131, 357 (Plasma insulin and growth hormone levels in obesity and diabetes. Adipose tissue, metabolism and obesity) 